\title{
A QUALITATIVE STUDY OF PERSPECTIVES OF CLINICIANS ON EXPECTED ANATOMICAL KNOWLEDGE OF AN INDIAN MEDICAL GRADUATE FOR SAFE CLINICAL PRACTICE
}

\section{C.Swathi Poornima.}

Associate Professor, Department of Anatomy, Dr.Pinnamaneni Siddhartha Institute of Medical Sciences \& Research Foundation, Chinnaoutapalli, Gannavaram mandal, Krishna District, Andhra Pradesh, India.

\section{ABSTRACT}

Background: Anatomy is the basic science discipline dealt for $1^{\text {st }}$ M.B.B.S for the first two semesters. Detailed knowledge of human anatomy is a must for clinical examination and diagnosis. Students tend to memorize the subject with rote-learning without much emphasis on clinical application. An attempt has been made to collect and analyze the perspectives and opinions of clinicians regarding the anatomical knowledge and competencies to be attained by a medical graduate for safe clinical practice.

Materials and Methods: A qualitative study was conducted with in depth interviews of 20 clinicians of various specialties of Dr.PSIMS\&RF. Data was collected, documented, collated and categorized into themes and subthemes (THEMATIC ANALYSIS).

Results: The main themes derived from data included curriculum of $1^{\text {st }}$ MBBS course, teaching learning methods and competencies to be attained. Some of the sub-themes categorized under the themes included, increase in course duration, not a need for early clinical exposure in present scenario, incorporation of surface anatomy and radiology in the curriculum, broad emphasis on clinical application with integration of clinical and basic sciences. Others included promotion of use of latest gadgets and frequent revision in clinics. Self-directed learning and critical appraisal of medical literature were the predominant competencies identified. Conclusions: The present study clearly states a slight modification of present curriculum, introduction of advanced T-L methods and impressing upon major competencies as self-directed learning and better understanding of medical education. KEY WORDS: Curriculum, Clinical Practice, Themes, Clinical Application.

Address for Correspondence: Dr.C.Swathi Poornima, Associate Professor, Department of Anatomy, Dr.Pinnamaneni Siddhartha Institute of Medical Sciences \& Research Foundation, Chinnaoutapalli, Gannavaram mandal, Krishna District, Andhra Pradesh-521286, India. Mobile no: 9701199777

E-Mail: swathi79poornima@gmail.com

Access this Article online Quick Response code

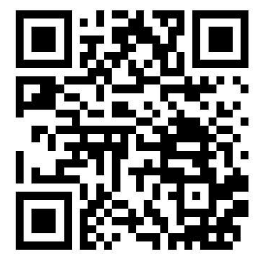

DOI: $10.16965 /$ ijar.2019.155

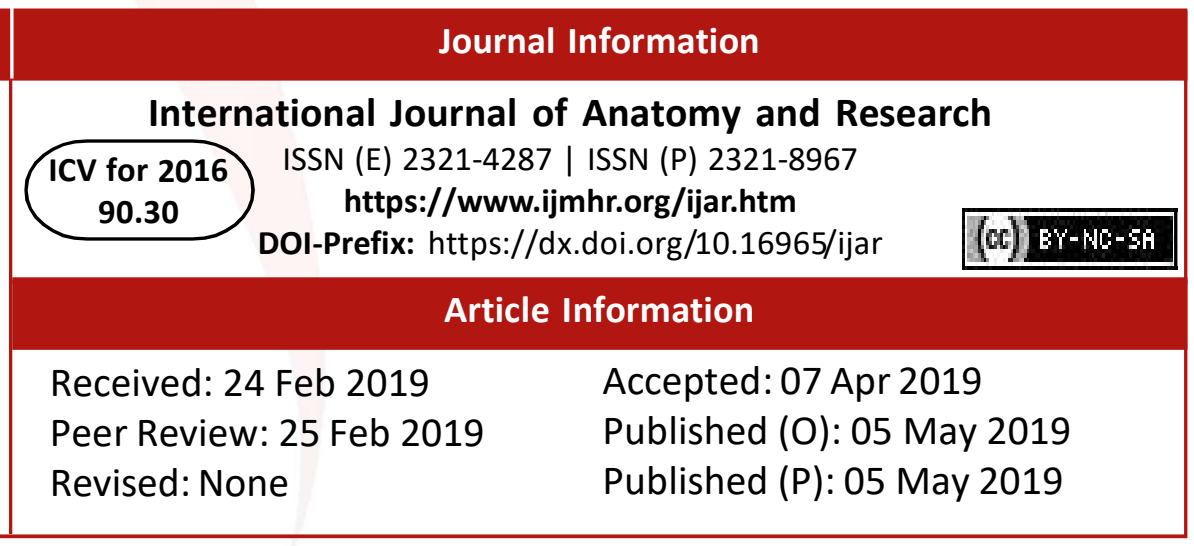

\section{INTRODUCTION}

Human anatomy is one of the basic science disciplines in $1^{\text {st }}$ year MBBS course. Detailed knowledge of anatomy is a pre-requisite for clinical reasoning and application in future clinical practice, more so in surgical specialities.
Students are expected to assimilate loads of information in short period of time, so they tend to memorize anatomy as subject by rote-learning with a profound negligence of intricacies and marvelous architecture of the human body. Impairing and worsening the situation, application 
of basic sciences especially anatomy has to be done several years after final university examination. No where throughout the course basic sciences are dealt in detail and depth accept in few specialties and revising only the regional part of the subjects in regular clinical postings. Hence,students find difficulty in retaining the subject relevant for application. On the advent of Competency based medical education (CBME), $\mathrm{MCl}$ has proposed certain competencies to be attained by an Indian Medical graduate in par with global standards. Modifications to some extent in the present curriculum of $1^{\text {st }}$ MBBS course are need of the hour. Inclusion of opinions and perspectives of clinicians might guide in setting competencies for future graduates. Previous studies on anatomical knowledge emphasized on perceptions of students rather than clinicians. A paucity of studies has been observed in relation to clinician's perspectives, only to find a few Western studies in literature which are more of quantitative studies. Author has made an attempt to analyze the perceptions of clinicians qualitatively and assess the involvement of clinicians in setting ground rules for and provide a reshape for core curriculum of anatomy. Institutional Ethical Committee clearance was obtained.

Objectives: The purpose of this qualitative study was to explore the views and opinions of clinical faculty regarding the expected knowledge of anatomy in graduates to perform routine and safe clinical practice.

\section{MATERIALS AND METHODS}

Setting: Dr.Pinnamaneni Siddhartha Institute of Medical Sciences \& Research Foundation.

Target population: Participants of the study consisted of 20 clinicians of various specialties.

Study design: Qualitative study.

Sample selection: Purposive sampling.

Method of data collection: Face to face indepth interviews were conducted with semi-structured questions with prior consent from the clinical faculty of all the cadres ranging from Head of the departments to Assistant Professors. Interviews were conducted in the private cabins of the faculty. Responses of the interviewees were collected as hand written notes and each interview was allotted with a number for future reference. Conduction of interviews was stopped when the responses of interviewees appeared repeated and data collected did not yield any newer information, this is referred to as data saturation in qualitative studies. Documents with thick descriptions were compiled .Data was organized into retrievable sections as Microsoft word documents.

Data analysis: Thematic analysis was applied. Thematic analysis is the process of identifying patterns or themes with qualitative data $[1,2]$. The six-phase frame work guide of Braun and Clarke of Thematic analysis was utilized for data analysis, which included following steps $[1,2]$ :

Fig. 1: Braun and Clarke six-phase guide for thematic analysis [1].

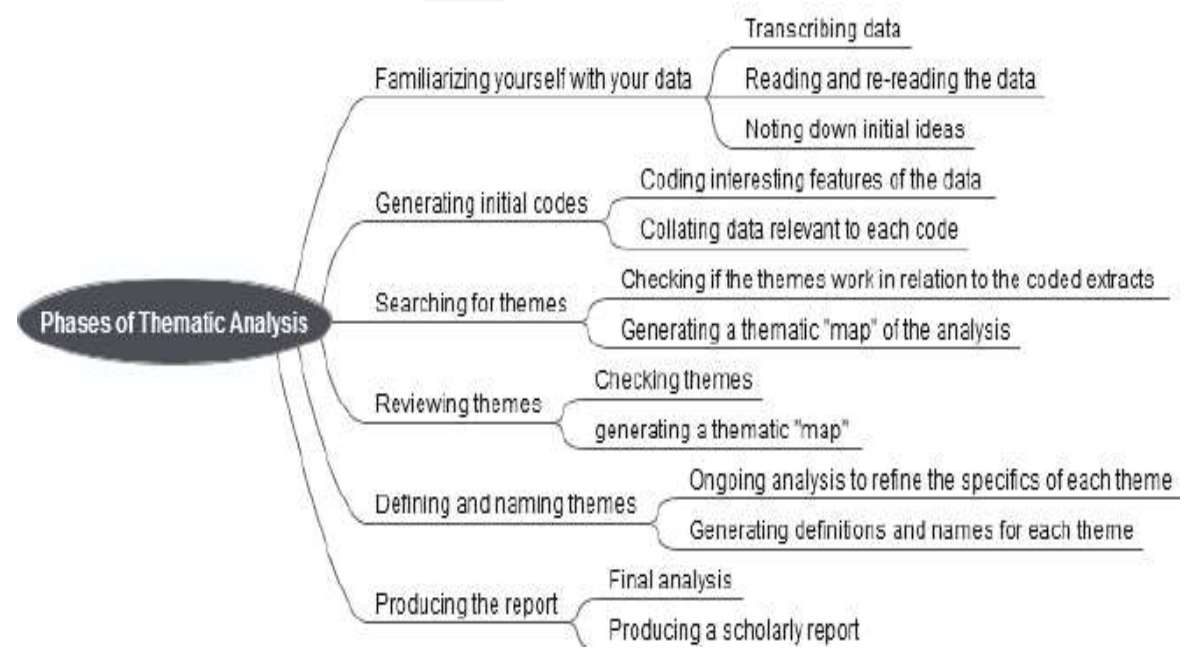


Step: 1 Familiarizing with data (read and re-read the available data.)

Step: 2 Generate initial codes (condensing and contracting the data available, important key statements, interesting features, words and phrases are coded systematically and are highlighted with different colours and collated into relevant codes.)

Step: 3 Search or identifying themes (collated codes are categorized into potential themes relevant from data)

Step: 4 Review themes (checking in whether the themes derived are coherent and different and relevant to the coded extracts and data set, generating a" thematic map").

Step: 5 Defining and naming the themes (final refinements of the themes and the aim is to identify essence of what each theme is.)

Step: 6 Write up or producing the report

\section{RESULTS}

Three main themes emerged from interviews of 20 clinicians by thematic analysis using an inductive approach, where themes generated or identified are strongly related and linked to the data collected. Semantic themes are identified with the explicit and surface meanings of data and the analysis did not emphasize much beyond what the participants have said or has been written. The themes were Curriculum, teaching-learning methods and competencies.

Curriculum: Most of the participants recommended minutiae alterations in the core curriculum of anatomy. Duration of $1{ }^{\text {st }}$ year MBBS course was of concern by many. Most of the interviewees preferred one and half year of course duration which would enhance detailed understanding of the subject with intricacies. As one of the clinician put it:

"in depth learning requires sufficient and more time". (Interviewee 6)

"Curriculum is generalized, it is up to basic science board of education, emphasis is on strong basics in preclinical years". (Interviewee 2)

Medical Council of India in its revised regulations has proposed for early clinical exposure. When this issue was posed to the participants, there was a mixed response with some favoring it and others rejecting. One of the participant highlighted:

"without preliminary knowledge of anatomy ,physiology and biochemistry, which is the need of the hour--not necessary, early clinical exposure."(Interviewee 6)

"No touch of anatomy, it would be like the K.G kids who forget everything then and there". (Interviewee 6)

Surface anatomy and Radiology were the most emphasized part in the anatomy curriculum. These two aspects are lagging behind in the curriculum of anatomy. Most participants were concerned regarding the lacunae in assessments and method of conducting examinations. "Students take the internals for granted and only concentrate more for passing the university examinations rather than learning the subject and its application". (Interviewee 1)

It is also reported that the levels of anatomical knowledge was below average in most of the students attending clinics, especially surgical branches and when asked about how the students were assessed, one of the participant said "sad state of affairs, I have asked a $8^{\text {th }}$ semester student the location and extent of thyroid gland, I was disheartened by the answer, later had mixed feelings of no reason." (Interviewee 10)

Teaching-Learning methods: Clinical application of basic sciences into clinical sciences was emphasized by most of the participants. Some of the clinicians came up with the view of implementing Problem -Based learning. "Problembased learning or case oriented teaching would be beneficial for surgical branches, for understanding the interventional procedures, basics of anatomy is must". (Interviewee 7) Vertical and Horizontal integration was highly appreciated by most of the clinicians and it was overwhelming response that most of the clinicians wanted to collaborate with the preclinical and para-clinical departments for the conduction of seminars, workshops, integrated teaching and case-based studies. Frequent revision of anatomy was suggested by some interviewees, they also opined for a 15-20 minutes lecture or demonstration of anatomy before starting up a surgical or a gynecological case study. It was 
interesting to note that the specialists wanted anatomists to take up the initial introduction of basics. One of the gynecologists preferred,

"recap and revision of supports of uterus, blood supply and structures in broad ligament would help the students in clinics for better understanding of Hysterectomy procedure". (Interviewee 2)

Many of the participants recommended the use of latest audio-visual aids, gadgets and recent advances in technology and media. Many of them came up with newer innovations as 3-D and 4-D, virtual imaging techniques and simulations for better understanding of the subject.

Competencies: As defined by Medical Council of India, Competency is the habitual and judicious use of communication, knowledge, technical skills, clinical reasoning, emotions, values and reflection in daily practice for the benefit of the individual and community being served. Analysis of the responses of the participants showed that most of them had a broad spectrum understanding and knowledge regarding the definition of competency. Many of the participants' opinions regarding competencies related and included self-directed learning, impressing and realizing the present stage of medical education and critical appraisal of medical literature leading to state of lifelong learner. One of the participants put forth: "competency should be able to know the basic applications and should know the concept of applying what they(students) read." (Interviewee 1) "medicine is all about application". (Interviewee 2)
Key statements of another participant. "Anatomy is marker of surgery", Physiology is marker of medicine". (Interviewee 5)

"Students should be encouraged to learn communication skills, ethics and professionalism". (Interviewee 6)

One of the interviewees' recommendations on competencies would definitely have profound impact on medical education; statements are interpreted as it is:

"we should not be pre-occupied with MET jargon". (Interviewee 8)

"Students should be made to realize all the basic sciences are for clinical management of the disease and restoring and maintaining health". (Interviewee 9)

"self-directed learning to be encouraged more and more. Evidence based diagnostic process, evidence based therapeutic selection, assessing cost benefit of management and sharing information with patient" are some of competencies expected of an Indian Medical graduate by one of the participant.(interviewee 8 )

"critical appraisal of medical literature and understanding of scientific import and relating to index patient" (interviewee 8) were some of competencies emphasized. Medical council of India identified 5 important roles of an Indian medical graduate in its revised regulations which include, Clinician, leader, communicator, lifelong learner, professional. Most of the participants insisted on the roles of clinicians, life-long learners and communicator as most important ones.

\begin{tabular}{|c|c|c|c|}
\hline \multirow{4}{*}{$\begin{array}{l}\text { Table 1: Major } \\
\text { themes and sub- } \\
\text { themes tabulated } \\
\text { with general quota- } \\
\text { tions. }\end{array}$} & THEMES/CATEGORIES & SUB-THEMES/CODES & GENERAL QUOTES \\
\hline & CURRICULUM & $\begin{array}{l}\text { *course duration } \\
\text { *early clinical exposure } \\
\text { *emphasis on surface anatomy and radiology } \\
\text { *pitfall/lacunae in assessment methods }\end{array}$ & $\begin{array}{l}\text { "indepth learning requires sufficient and more time" } \\
\text { "without basic preliminary knowledge of subject-not necessary, early } \\
\text { clinics" } \\
\text { "surface marking not there, how will student identify deep \& } \\
\text { superficial inguinal rings" } \\
\text { "rite to passage ,attendance taken liberally, practical skill } \\
\text { assessment is nil, below average levels and standards" }\end{array}$ \\
\hline & Teaching-learning methods & $\begin{array}{l}\text { *Clinical application \& introduction of problem } \\
\text { based learning. } \\
\text { *Integrated teaching } \\
\text { *Revisions and recaps of anatomy in clinics } \\
\text { *use of latest advances as teaching aids }\end{array}$ & $\begin{array}{l}\text { "health and illness: should understand illness of patient in relation to } \\
\text { basic sciences" } \\
\text { "Anatomy is marker of surgery, physiology is marker of medicine, } \\
\text { and integration plays a major role". } \\
\text { "just come to gynaec dept , take a } 15 \text { min class of anatomy for final } \\
\text { semester, that would be of more benefit to the student". } \\
\text { "you have right to use all latest gadgets in market,3D visuals, } \\
\text { artificial whole body models, essential anatomy online series and so } \\
\text { on" }\end{array}$ \\
\hline & Competencies & $\begin{array}{l}\text { *self-directed learning } \\
\text { *Impress and realize the present stage of } \\
\text { medical education(professional role) } \\
\text { *critical appraisal of medical literature(life-long } \\
\text { learner and communicator roles) }\end{array}$ & $\begin{array}{l}\text { "student should be made to realize, all the basic sciences are for } \\
\text { clinical management of the disease and restoring and maintaining } \\
\text { health". } \\
\text { "we should not be pre-occupied with medical education jargon". } \\
\text { "learning more \& more evidence based diagnostic process, assessing } \\
\text { cost benefit of management and sharing information with patients". }\end{array}$ \\
\hline
\end{tabular}




\section{DISCUSSION}

Qualitative research deals with independent reality which can be accessed only through human interpretation, which leads to multiple perspectives (interpretivism). The approach involves understanding of a phenomenon from the subject's perspective in natural settings. Themes from thick description are the units of analysis. Most of the studies in literature are quantitative analysis of anatomical knowledge, which analyzed responses of students rather than faculty. Few western studies have been identified which involved perceptions of clinicians.

Bergman et al [3] reviewed many articles on anatomical knowledge; they identified eight influential factors which affected anatomical knowledge of undergraduates. These included (1) teaching by nonmedically qualified teachers (2) the absence of a core anatomy curriculum, (3) decreased use of dissection as a teaching tool, (4) lack of teaching anatomy in context, (5) integrated curricula(problem-based learning or systems -based curricula), (6) inadequate assessment of anatomical knowledge, (7) decreased anatomy teaching time, and (8) neglect of vertical integration of anatomy teaching. Most of the influential factors were also identified in present study except for teaching by nonmedically qualified teachers. Bergman et al identified that in order to fit anatomy curriculum into available time, all aspects of anatomy have to be pruned, this will include deleting specific body regions, embryology, and histology from the educational program. They also emphasized that anatomy should be taught within relevant contexts, such as clinical skills, pathology or radiology. Similar responses from the interviewees were also observed in the present study, though the approach was different.

Namita Sharma [4] has rightly appreciated the lack of an integrated vertical approach to the subject. It was also emphasized in the editorial that anatomical knowledge, as required by a medical student, should be viewed as conjunct to the clinical sciences and, to achieve this, it is imperative to refrain from providing(and expecting while assessing the student) unnecessary details. She pointed out the fact that the time allocated to the basic sciences has been reduced and the current scenario provides less than a year's exposure before the student is required to appear for the university examination. She also emphasized on self-study and revision of relevant portions of the basic sciences which would aid in a conceptual understanding of a disease or a disorder. All the major themes in present study also state the above factors to influence anatomical knowledge. Staskiewicz et al [5] has conducted a survey on clinicians regarding their thinking of anatomical knowledge of medical students .As a result of the survey it was observed that surgical specialists had a significantly lower opinion on knowledge than had medical specialists. Most of the suggestions were related to introducing clinical applications of anatomical knowledge.

Fig. 2: Relationship of major themes with anatomical knowledge. (Thematic map).

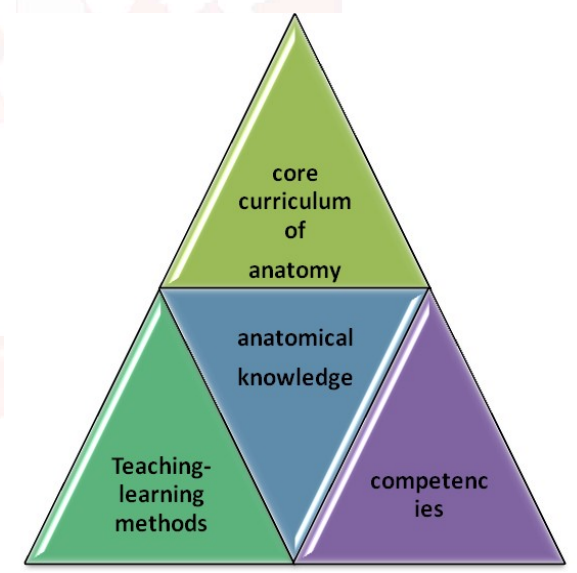

Courtney P.Orsburn et al [6] gathered physicians' opinions about anatomy core curriculum .The primary aim of their study was to assess the importance of a gross anatomy course by soliciting the opinions of 93 physicians from a range of specialties. Overall, only medical imaging (radiology) received high importance, they suggested that students revisit anatomy through a vertically integrated curriculum tailored to provide specialty-specific anatomical training. Rao $\mathrm{KH}$ et al [7] in their study for enhancing preclinical education in Japan, identified two critical changes. The first, content must be made interesting to students by emphasizing its clinical importance, through close collaboration between preclinical and clinical departments, thus they suggested the surgical faculty to 
incorporate in the organization and teaching of the anatomy curriculum. The second change that must be implemented is to make learning process more appealing to the students. This according to them can be facilitated by the use of any of several commercial IT programs that make learning in anatomy both dynamic and engaging.

In present study clinicians have provided their inputs regarding the latest innovations in teaching and learning methods which would enhance the learning and thought process of the medical students. A quantitative study was conducted on the stakeholder perceptions (medical students, clinicians, anatomy educators) by Amgad Sbayeh et al [8] for designing a curriculum in anatomy which fulfills the criteria for safe clinical practice. The study adds that the students, clinicians and anatomy educators differ with respect to perceptions of the relevance of anatomy education to medicine and clinical practice. Comparison of student, educator and clinicians perspectives highlights the challenge of tailoring anatomy education to both foster the development of professionalism and to increase student readiness to function effectively in a clinical role. Present study included perspectives of clinicians and their role to be played for reshaping the curriculum of anatomy was considered.

In the order to maintain the rigor and quality of the present study, the data collection, analysis and reporting part has been peer examined (audit) and in order to ensure that the description and/or interpretation does in fact reflect their experiences, participants are approached for checking their responses, this process is referred to as member-check which maintains the credibility of the study .Confirmability of the study was maintained by stringent attempts to sustain neutrality by the researcher [9].

The study limitations include transferability factor which in terms of quantitative studies refers to generalisability, one factor is the study sample being small and how far the results of the study apply to other groups and environments is beyond the researcher's area. Further research on this aspect can be carried on for policy and decision making at the level of health universities.

\section{CONCLUSION}

Three main themes have emerged from the analysis of qualitative data of clinicians which included Curriculum, teaching-learning methods and competencies. Most of the participants suggested inclusion of surface marking and radiology as a part of $1^{\text {st }}$ year curriculum of anatomy. Integrated teaching was the preferred method for enhancing clinical application of basic sciences into clinical sciences .Most of them opined revision and anatomy to be retaught in later years of MBBS course. Competencies identified included self-directed learning, critical appraisal of medical literature, lifelong learner and professionalism. Present study emphasizes on the involvement of clinicians in developing, reshaping and providing guidelines for better understanding of anatomy as a subject as well as its relevant application in clinics. Faculty from all specialties should be incorporated into the board of medical education for $1^{\text {st }}$ year MBBS curriculum for policy and decision making .Suggestions of faculty regarding assessment methods is of paramount importance which would definitely affect the outcome.

\section{ACKNOWLEDGEMENTS}

I am grateful to all the faculty of Dr.PSIMS\&RF \& RF for supporting me in my endeavor. I am thankful to the Medical Superintendent and Heads of all the clinical departments for taking out time and cooperating with me.

\section{Conflicts of Interests: None}

\section{REFERENCES}

[1]. Braun V Clarke V.Using thematic analysis in psy chology. Qualitative research in psychology.2006; 3(2).pp.77-101.

[2]. Moira Maguire, Brid Delahut .Doing a thematic analysis: A practical step-by-step guide for learning and teaching scholars.AISHE-J.2017; 8(3):335133514.

[3]. Esther M Bergman, Inge W H Verheijen et al. Influences on Anatomical knowledge: The complete arguments. Clinical Anatomy.2014; 27:296-303.

[4]. Namita Sharma. Teaching of Human Anatomy: The Indian perspective. Missing the woods for the trees? Rev Arg de Anat Clin.2014;6(1):6-8. 
[5]. Staskiewicz GJ, Walczak E et al .What do clinicians think of the anatomical knowledge of medical students? Results of a survey. Folia Morphol (Warzs).2007May; 66(20):138-42.

[6]. CourtneyP.Orsburn, RebeccaS Kaiser et al.Physicians opinions about an anatomy core curriculum: A case for medical imaging and vertical integration. Anat Sci Educ.2013; 7:251-261.

[7]. RaoKH, RaoRH.Perspectives in medical education 8.Enhancing preclinical education in Japan with clinically focused, interactive anatomy curriculum.Keio J Med.2009; 58(4):2015.
[8]. Amgad Sbayeh, Mohammad A Qaedi Choo et al. Relevance of anatomy to medical education and clinical practice: perspectives of medical students, clinicians and educators. Perspect Med Educ.2016; 5:338-346.

[9]. Claire Anderson .Presenting and evaluating qualitative research. American Journal of Pharma ceutical Education.2010; 74(8) article141.

How to cite this article:

C.Swathi Poornima. A QUALITATIVE STUDY OF PERSPECTIVES OF CLINICIANS ON EXPECTED ANATOMICAL KNOWLEDGE OF AN INDIAN MEDICAL GRADUATE FOR SAFE CLINICAL PRACTICE. Int J Anat Res 2019;7(2.2):6509-6515. DOI: 10.16965/ijar.2019.155 